\title{
Cobalt adsorption on the nano-hydroxyapatite matrix: isotherm and kinetic studies
}

\author{
V.N. NARWADE ${ }^{1,2}$ and R.S. KHAIRNAR ${ }^{1 *}$ \\ ${ }^{1}$ School of Physical Sciences, Swami Ramanand Teerth Marathwada University, Nanded, 431-606 Maharashtra, India. \\ ${ }^{2}$ University of Maribor, Institute for Engineering Materials and Design, 17 Smetanova St., SI-2000 Maribor, Slovenia
}

\begin{abstract}
Cobalt radionuclide is one of the prime contaminants generated during operation of pressurized heavy water. The paper reports the study of cobalt adsorption on hydroxyapatite (HAp) nanoceramic. A modified wet chemical precipitation method is used for HAp synthesis. The HAp nano-material is characterized by XRD, FTIR, TG/DTA, AFM, SEM, and EDAX. Experiments are performed in batches to observe the effect of cobalt adsorption on HAp matrix. The adsorption of cobalt on HAp is examined at room temperature. The isotherm and kinetic studies showed that the Freundlich isotherm and pseudo-second order model are the best choices to describe the nature of adsorption.
\end{abstract}

Key words: hydroxyapatite, cobalt, adsorption, XRD, SEM.

\section{Introduction}

Revelation of heavy metals to man, which are discharged into bodies of water via industrial operations, human practices, etc. even at trace levels, is believed to be a great risk with its long-term effects [1]. Heavy metals are not biodegradable and tend to accumulate in living organisms, causing various diseases and disorders [2]. When their hostile effects and toxicity are considered, it is critical to remove heavy metal ions from water resources. There has been a rising interest and hard work put to improve the efficiency of conventional techniques of treating metal-contaminated effluents. Among the conventional physico-chemical methods, adsorption has been extensively employed because of its ease of use and effectiveness [3, 4]. Cobalt, a natural element present in certain ores of the Earth's crust, which exists in the form of various salts, is essential to life in trace amounts due to being an essential component of Vitamin B12. It has also recently been identified as an integral part promoting blood cell production. Pure cobalt is an odourless, steely-gray, shiny, stiff metal [5]. Cobalt has both advantageous and detrimental effects on health. Cobalt may occur with oxidation levels from -1 to +4 , but in nature it occurs usually as a di-valent cation $\mathrm{Co}^{2+}$ (cobalt compounds). In erosive environment it easily undergoes oxidation from $\mathrm{Co}^{2+}$ to $\mathrm{Co}^{3+}$ and creates the complex anion [6]. According to international standards, the allowed restrictions for amounts of cobalt in irrigation water and livestock watering is $0.05 \mathrm{mg} \mathrm{dm}^{-3}$ [5]. Cobalt may cause mutations in living cells where, as its ionizing radiation, it is associated with an increased risk of developing cancer [7]. Therefore, their optimal removal from wastewater is a foremost important global issue for preserving ecology. Generally, the techniques employed for heavy metal removal include ion exchange, adsorption, filtration, electrodeposition,

*e-mail: rskhairnarsps@gmail.com reverse osmosis, etc. [8-10]. It was reported that apatite-group minerals with special crystal characteristics are the most promising materials in the treatment of wastewater containing fluoride and heavy metals [11]. Moreover, as a member of apatite mineral family, hydroxyapatite $\left(\mathrm{Ca}_{10}\left(\mathrm{PO}_{4}\right)_{6}(\mathrm{OH})_{2}, \mathrm{HAp}\right)$ is an ideal material for the discarding radioactive contaminants having long life because of its elevated sorption capacity for heavy metals, low water solubility, availability, low cost, and high stability under oxidizing and reducing conditions. The sorption mechanisms of heavy metals are diverse and mainly include processes such as ion exchange, dissolution/precipitation, and formation of surface complexes $[12,13]$.

\section{Experimental}

2.1. Materials and methods. Calcium nitrate tetrahydrate $\left(\mathrm{Ca}\left(\mathrm{NO}_{3}\right)_{2} \cdot 4 \mathrm{H}_{2} \mathrm{O}\right)$, di-ammonium hydrogen phosphate $\left(\left(\mathrm{NH}_{4}\right)_{2} \mathrm{HPO}_{4}\right)$ and cobalt nitrate $\left(\mathrm{Co}\left(\mathrm{NO}_{3}\right)_{2} \cdot 6 \mathrm{H}_{2} \mathrm{O}\right)$ standard samples were purchased from Merck specialties Pvt. Ltd. Ammonia $(25 \%)$ was used for adjusting the $\mathrm{pH}$ of the mixture. The cobalt solution was prepared from the nitrate salt (AR) grade.

2.2. Synthesis of HAp. The synthesis of HAp is performed according to the literature previously reported in Mahabole et al. using the wet chemical method [14]. Pure grade calcium nitrate, di-ammonium hydrogen phosphate, and ammonium hydroxide were used as the starting chemicals. The stoichiometry of the calcium nitrate and di-ammonium phosphate solutions is adjusted so as to get the theoretical $(\mathrm{Ca} / \mathrm{P})$ molar ratio close to 1.67 [15]. The precipitation is performed by slow addition of di-ammonium phosphate solution $(0.6 \mathrm{M})$ to calcium nitrate solution $(1 \mathrm{M})$ under continuous and gentle stirring at $80^{\circ} \mathrm{C}$. The $\mathrm{pH}$ of the reaction mixture is adjusted by the addition of $\mathrm{NH}_{4} \mathrm{OH}$. As a result of reaction, milky precipitate is obtained. In the wet chemical process, the precipitate is continuously stirred 
for 5 hours using a magnetic stirrer. The resulting white precipitate is washed thoroughly three times with double-distilled water, dried in an oven at about $100^{\circ} \mathrm{C}$ for 2 hours and further kept in a high-temperature furnace at $1000^{\circ} \mathrm{C}$.

2.3. Characterization. The synthesized hydroxyapatite powders are characterized by X-ray diffraction (XRD), atomic force microscopy (AFM), Fourier transform infrared spectroscopy (FTIR), thermal gravimetric/differential thermal analysis (TG/DTA), scanning electron microscopy (SEM) and energy dispersive $\mathrm{x}$-ray diffraction (EDAX). X-ray diffraction patterns are obtained with an X-ray diffractometer with $\mathrm{CuK}_{\alpha}$ $(\lambda=1.543 \AA$ ) incident radiation. The XRD peaks are recorded in the $2 \theta$ range of $20^{\circ}-60^{\circ}$. AFM is used to observe the topography of samples at nanoscale resolution with variable magnification in the range of $1 \mu \mathrm{m}-400 \mathrm{~nm}$. FTIR spectrophotometer is used for identification of functional groups present in the HAp ceramic. The samples are scanned from $3700 \mathrm{~cm}^{-1}$ to $400 \mathrm{~cm}^{-1}$ with the average of 45 scans. Thermal methods are based on the measurement of dynamic relationship between temperature and some properties of the system such as mass, heat of reaction or volume. Hence, the thermal properties of HAp are verified with the help of TG/DTA analyzer system. Scanning electron microscopy was used to visualize surface topography, while energy-dispersive X-ray analysis used for elemental analysis. The Co-HAp samples, which are obtained after sorption experiments, are characterized by FTIR, AFM, SEM, and EDAX.

2.4. Batch adsorption experiments. The adsorption experiments of $\mathrm{Co}^{2+}$ are performed according to the batch method. Various conical flasks containing varied amount of HAp adsorbent and $20 \mathrm{ml}$ of cobalt solution with the initial $\mathrm{pH}$ of $5.8 \pm 0.1$ are placed in a constant air bath oscillator to vibrate at room temperature. After a certain, fixed period of time, the HAp is separated from the solutions using a filter paper. The initial and final metal concentrations are determined by a UV-Vis spectrometer at a wavelength of $511 \mathrm{~nm}$. The removal percentage of cobalt by hydroxyapatite is calculated by the following formula [16]:

$$
\% \text { removal }=\frac{C_{i}-C_{e}}{C_{i}} \cdot 100,
$$

where: $C_{i}$ and $C_{e}$ are the initial and final cobalt concentrations in $\mathrm{mg}^{-1}$, and cobalt adsorption capacity of hydroxyapatite at equilibrium is observed by [17]:

$$
\mathrm{q}_{\mathrm{t}}=\frac{\mathrm{V}}{\mathrm{W}}\left(\mathrm{C}_{\mathrm{i}}-\mathrm{C}_{\mathrm{e}}\right),
$$

where: $\mathrm{q}_{\mathrm{t}}$ is the adsorption capacity of an adsorbent in $\mathrm{mg} \mathrm{g}^{-1}$ at time $\mathrm{t}, \mathrm{V}$ is the volume of adsorbate in litres, and $\mathrm{W}$ is the mass of adsorbent in grams. After the removal of Co is complete, the HAp samples are separated by filtering and dried. FTIR, AFM, SEM and EDAX analyses are carried out on the dried samples to examine the changes in the HAp matrix after the adsorption process.

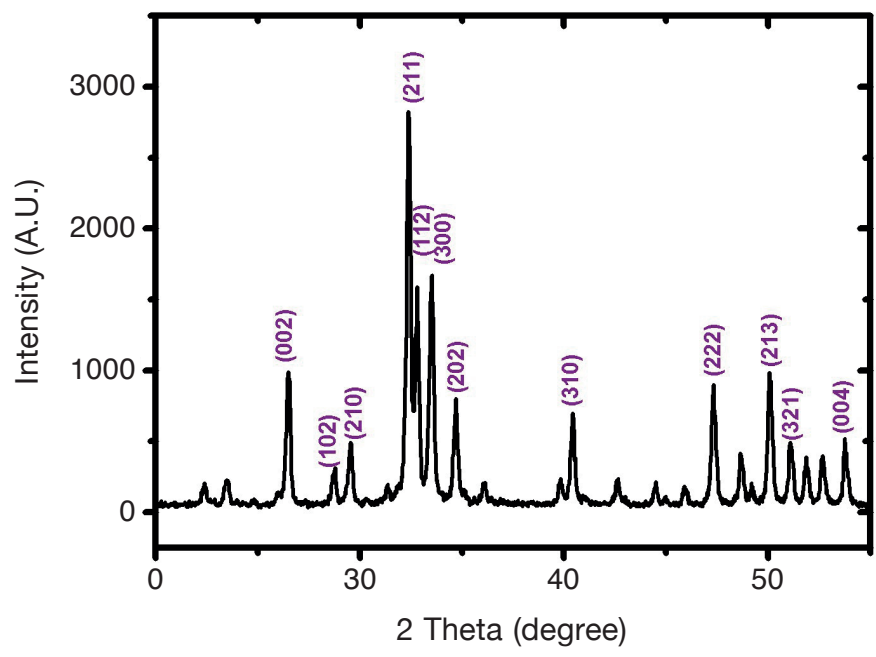

Fig. 1. XRD pattern of the synthesized HAp nanopowder displaying sharp diffraction peaks

\section{Results and discussion}

3.1. XRD study. Figure 1 shows that the characteristic peaks of HAp are at $2 \theta$ angle of $32.41,33.58,26.79,50.25,47.32,34.71$, 40.57 etc. From this, it can be observed that most of the peaks fit well with hexagonal hydroxyapatite phase, which represents the lattice parameters: $\mathrm{a}=\mathrm{b}=9.42 \AA, \mathrm{c}=6.88 \AA$ [18]. The phase analysis of crystalline HAp shown was carried out with the help of JCPDS data card no. 09-0432. The grain size D of HAp is calculated, which turns out to be $24 \mathrm{~nm}$, as calculated by Scherrer formula, which is expressed as [14]:

$$
\mathrm{D}=\frac{\mathrm{k} \lambda}{\beta \cos \theta},
$$

where: $\lambda$ is the X-ray wavelength in nanometers $(\mathrm{nm}), \beta$ is the peak width of the diffraction peak profile at half its maximum height in radians, and $\mathrm{k}$ is a constant related to crystallite shape, normally taken as 0.9 .

3.2. AFM study. AFM experiments are conducted in non-contact mode using a glass probe. An AFM image shows detailed topography of the nano-sized porous surface. Fig. 2 shows HAp

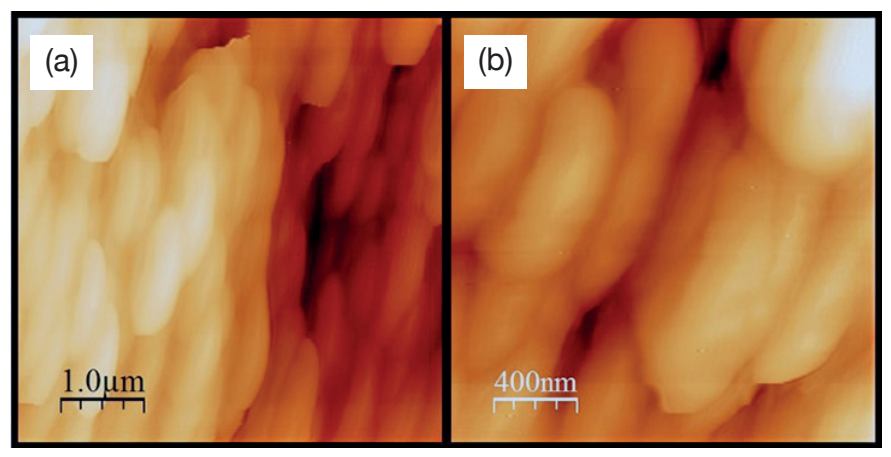

Fig. 2. AFM of the synthesized HAp nanopowder at magnification (a) $1 \mu \mathrm{m}$ and (b) $400 \mathrm{~nm}$ 


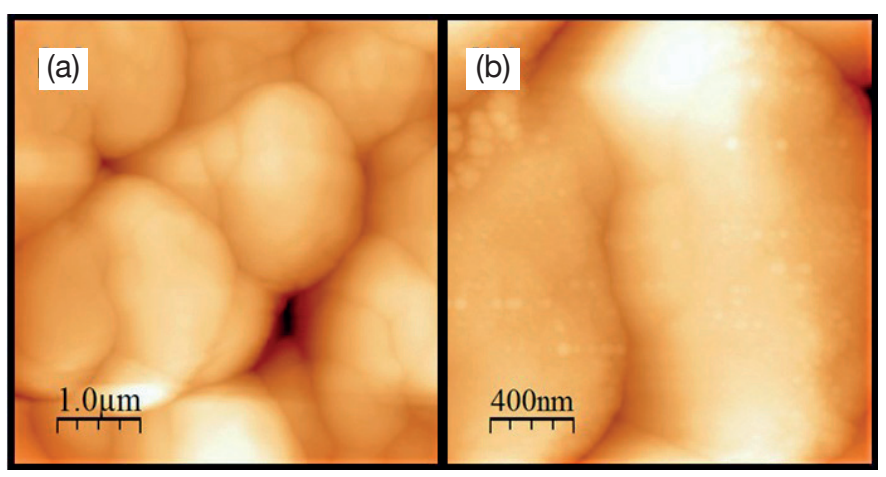

Fig. 3. AFM of HAp after Co sorption at magnification (a) $1 \mu \mathrm{m}$ and (b) $400 \mathrm{~nm}$

surface composed of smooth-faceted grains with uniform dimensions. It can be seen that the size of pores varies in the range of $100 \mathrm{~nm}-200 \mathrm{~nm}$ for the HAp matrix. Fig. 3 shows the AFM of HAp after Co sorption. Fig. 3(b) is a magnified portion of Fig. 3(a), which clearly denotes the dotted spot, which is a clear indication of Co sorption on HAp surface.

3.3 FTIR study. FTIR spectra given in Fig. 4 reveal the chemical composition of the HAp and HAp powder after Co sorption. The spectra indicate a presence of a phosphate group and a hydroxyl group in HAp. The IR spectra of HAp indicate the absorption bands at $3572 \mathrm{~cm}^{-1}$ and $3433 \mathrm{~cm}^{-1}$, corresponding to the stretching mode of the hydroxyl group. The hydroxyl libration mode is found to be present at $632 \mathrm{~cm}^{-1}$. The band at $1622 \mathrm{~cm}^{-1}$ reveals $v_{3}$ vibrations of the hydroxyl group. The band at $963 \mathrm{~cm}^{-1}$ and $974 \mathrm{~cm}^{-1}$ are caused by the $v_{1}$ mode of $\left(\mathrm{PO}_{4}^{3-}\right)$ [14]. The FTIR spectra of HAp after cobalt sorption show the presence of individuality bands of hydroxyl and

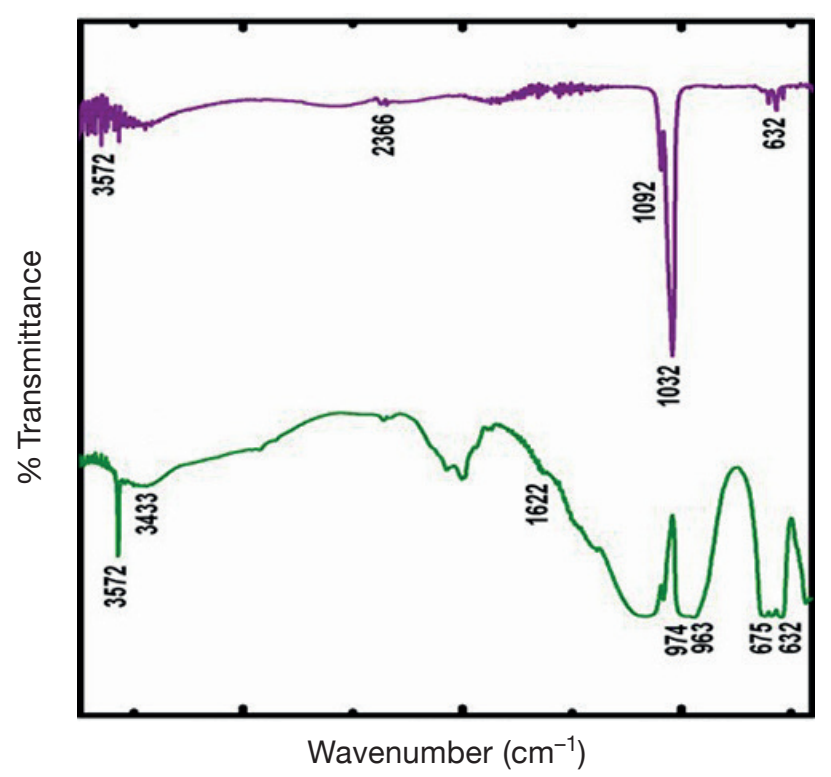

Fig. 4. FTIR spectra of the (a) synthesized HAp nanopowder and (b) HAp after Co sorption phosphate species. The absorption band appearing $3572 \mathrm{~cm}^{-1}$ corresponds to the stretching vibration mode of the hydroxyl group. The absorption bands at $1032 \mathrm{~cm}^{-1}$ and $1092 \mathrm{~cm}^{-1}$ are caused by $v_{3}$ stretching of the phosphate group $\left(\mathrm{PO}_{4}^{3-}\right)$. Along with these peaks, the fractional replacement of $\mathrm{Ca}^{2+}$ by $\mathrm{Co}^{2+}$ results in the formation of a new phosphate peak at $903 \mathrm{~cm}^{-1}$. The intensity of the newly developed peak decreases with the increase in cobalt concentration [13].

3.4. TG/DTA study. TG/DTA graph of HAp is displayed in Fig. 5. The slightly sloped TGA curve indicates thermal stability of the material. During heating up to $1000^{\circ} \mathrm{C}$, the HAp material undergoes a weight loss of $16 \%$, obviously attributed to desorption of water and $\mathrm{CO}_{2}$ molecules. Corresponding to the changes in TGA, there are changes in DTA. The exothermic

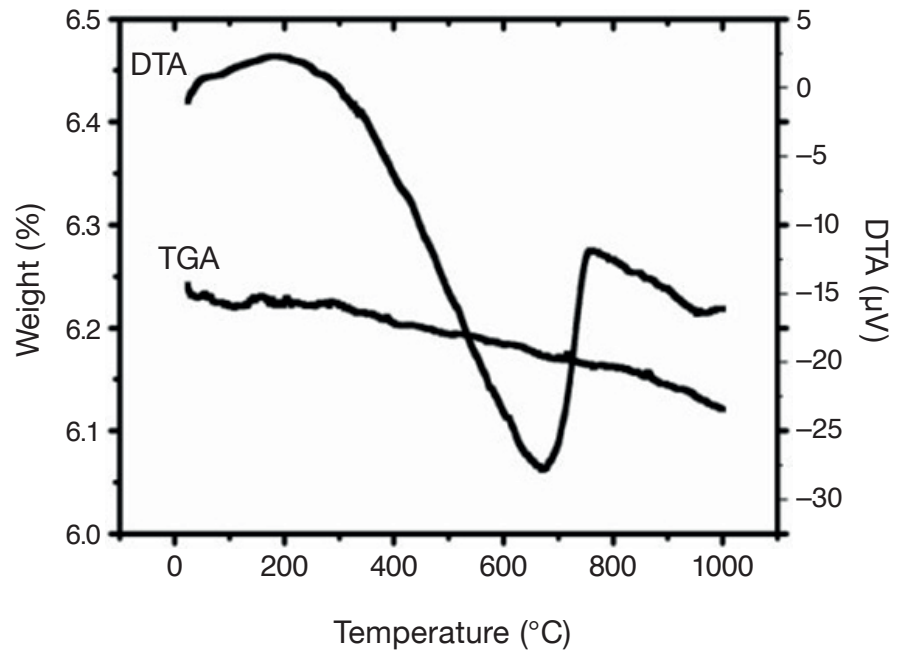

Fig. 5. TG/DTA curve of the synthesized HAp nanopowder

and endothermic peaks are present due to the removal of the hydroxyl group and breakdown of the residual $\mathrm{CaCO}_{3}$ group. Above $1000^{\circ} \mathrm{C} \mathrm{HAp} \mathrm{decomposes} \mathrm{into} \mathrm{tetra} \mathrm{calcium} \mathrm{phosphate}$ and $\alpha$-TCP according to the following reaction [19]:

$$
\mathrm{Ca}_{10}\left(\mathrm{PO}_{4}\right)_{6}(\mathrm{OH})_{2} \rightarrow \mathrm{Ca}\left(\mathrm{PO}_{4}\right)_{2}+2 \alpha \mathrm{Ca}\left(\mathrm{PO}_{4}\right)_{2} \mathrm{O}+\mathrm{H}_{2} \mathrm{O}
$$

Thus, it is confirmed that HAp is thermally stable up to $1000^{\circ} \mathrm{C}$

3.5. SEM and EDAX analysis. The SEM image of synthesized HAp nanopowder indicates a porous nature throughout the HAp matrix. The porous nature directly relates to higher availability of adsorption sites. The average pore size is about 0.5 micron and the particles are seen to agglomerate exhibiting high porosity, which is an ideal property for the material to be used as an efficient adsorbent. The elemental analysis of HAp was done using EDAX. It indicates the elemental composition of materials. HAp constitutes mainly of calcium and phosphate groups which are indicated in EDAX spectra. The weight percentages of $\mathrm{Ca}, \mathrm{P}, \mathrm{O}$, and $\mathrm{C}$ are found to be $21.57 \%, 12.58 \%, 54.98 \%$, and $10.87 \%$, respectively. The 
SEM image of HAp after cobalt sorption is shown in FIG. After cobalt sorption, the porous nature of HAp is collapsed, showing adsorption of cobalt on the HAp matrix, while EDAX spectra show the characteristic peak of cobalt. The weight percentages of $\mathrm{Ca}, \mathrm{Co}, \mathrm{P}, \mathrm{O}$, and $\mathrm{C}$ are $16.95 \%, 6.06 \%, 9.44 \%$, $60.77 \%$, and $6.78 \%$, respectively. The elemental analysis also reveals that $\mathrm{Ca}^{2+}$ undergoes ion exchange with $\mathrm{Co}^{2+}$ during the shaking process.

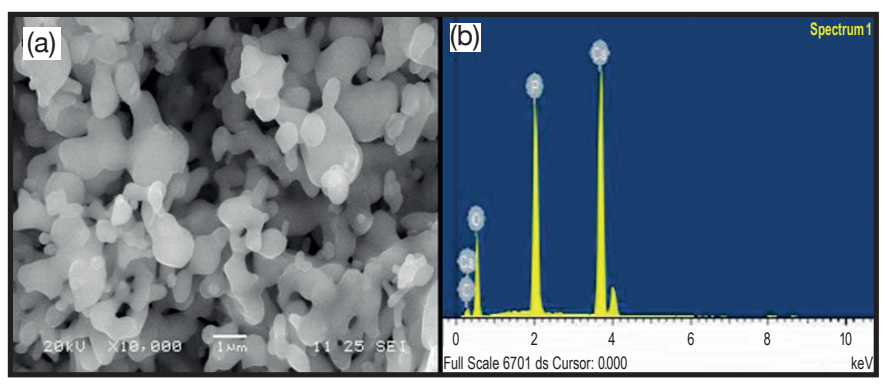

Fig. 6. (a) SEM image and (b) EDAX spectra of synthesized HAp nanopowder

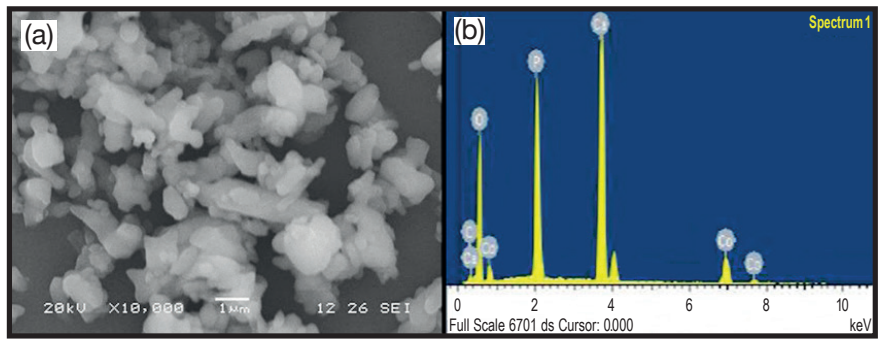

Fig. 7. (a) SEM image and (b) EDAX spectra of HAp after Co sorption

3.6. Effect of initial metal concentration. Sorption isotherms were obtained by equilibrating HAp with metal solutions of different initial concentrations - 0.02-0.07 mol, i.e. from 270 $\mathrm{mg}^{-1}$ to $1890 \mathrm{mg} \mathrm{l}^{-1}$ - for $120 \mathrm{~min}$. The obtained data was used to predict the nature of adsorption isotherms.

3.7. Effect of contact time. The effect of contact time on each metal sorption was studied in different time intervals, ranging from $10 \mathrm{~min}$ to $70 \mathrm{~min}$ with the initial fixed cobalt metal concentration $\left(\mathrm{C}_{\mathrm{i}}\right)$ of $0.03 \mathrm{~mol}$ i.e. $870 \mathrm{mg} \mathrm{l}^{-1}$. After the completion of the reaction, the conical flasks were taken out and the HAp adsorbents were separated, followed by the determination of the residual metal concentrations. Fig. 8 shows the percentage removed by different adsorbent concentrations viz. $150 \mathrm{mg} \mathrm{l}^{-1}$, $200 \mathrm{mg} \mathrm{l}^{-1}, 300 \mathrm{mg} \mathrm{l}^{-1}$. Here it is observed that as the concentration of HAp sorbent is increasing, the cobalt sorption efficiency also increases. For the HAp dose of $300 \mathrm{mg}^{-1}$, the removal efficiency is nearly $87 \%$, while for $150 \mathrm{mg} \mathrm{l}^{-1}$ and $200 \mathrm{mg} \mathrm{l}^{-1} \mathrm{HAp}$, it is $84 \%$ and $85 \%$ respectively, for a contact duration of $30 \mathrm{~min}$.

3.8. Effect of HAp dosage. The suspensions containing different amounts of HAp $-50 \mathrm{mg} \mathrm{l}^{-1}$ to $300 \mathrm{mg}^{-1}-$ from the

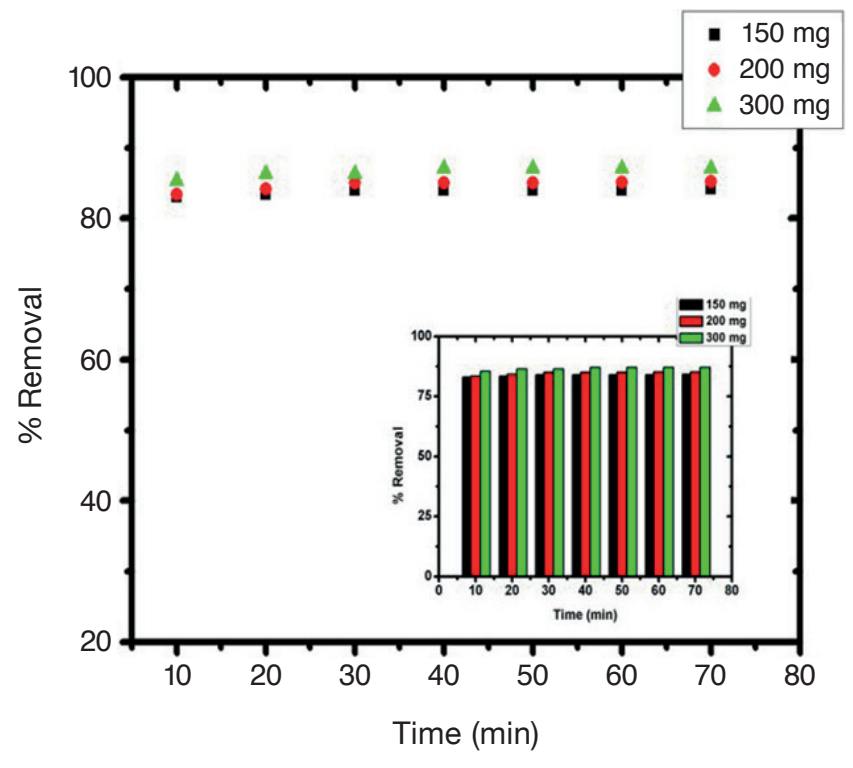

Fig. 8. Effect of the contact time on cobalt adsorption by HAp nanopowder at given conditions: $\mathrm{C}_{\mathrm{i}}=870 \mathrm{mg} \mathrm{l}^{-1}$ with different adsorbent HAp concentrations

metal solution are placed in an air bath shaker. After separation, the residual metal concentrations in the solutions are measured. At lower HAp doses, the percentage of sorption is low. As the HAp doses are increased, the HAp tends towards equilibrium. It is seen that HAp doses achieve their maximum removal efficiency after $200 \mathrm{mg} \mathrm{l}^{-1}$. The maximum removal efficiency was found to be as high as $87 \%$.

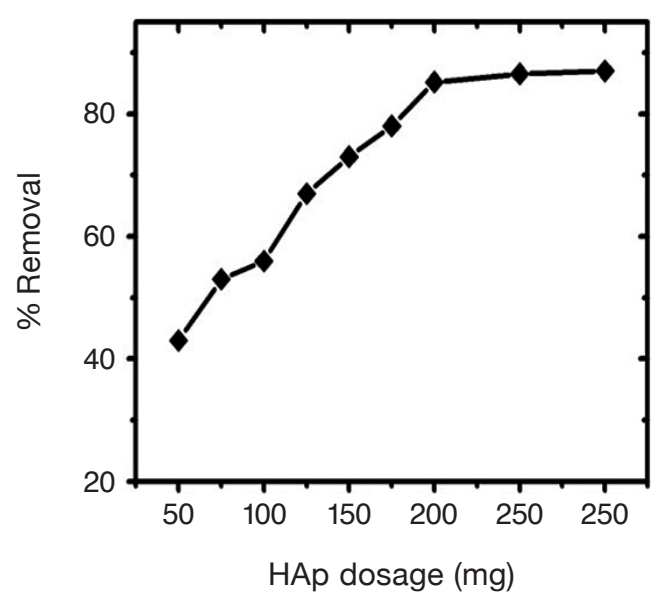

Fig. 9. Effect of the HAp doses on cobalt adsorption at given conditions: $\mathrm{C}_{\mathrm{i}}=870 \mathrm{mg} \mathrm{l}^{-1}$

3.9. Effect of $\mathbf{p H}$. The $\mathrm{pH}$ of solution is an influential factor which affects the adsorption phenomena. The percent removal increases as the $\mathrm{pH}$ increases, and maximum adsorption occurs at a $\mathrm{pH}$ around 6 . Here, at higher $\mathrm{pH}$, heavy $\mathrm{Co}$ ions tend to form precipitation. Therefore, the $\mathrm{pH}$ study observed values up to $\mathrm{pH} 7$. 


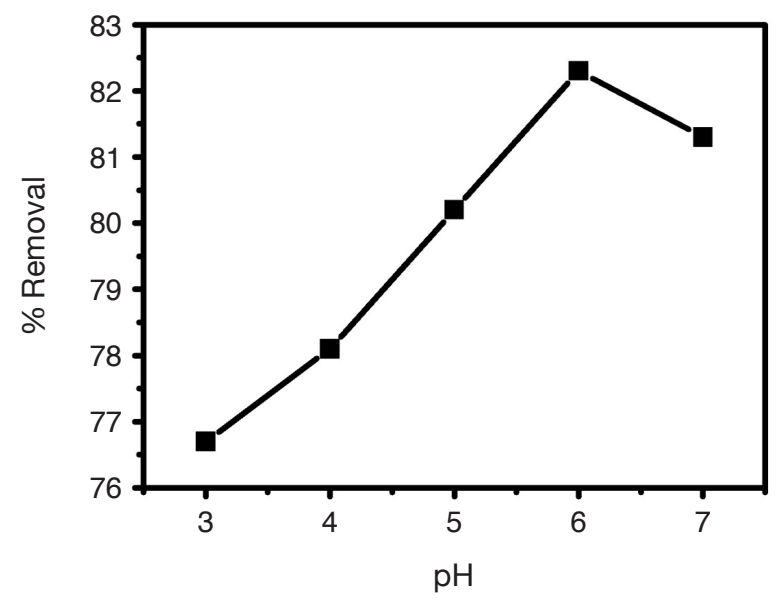

Fig. 10. Effect of $\mathrm{pH}$ on cobalt adsorption at given conditions: $\mathrm{C}_{\mathrm{i}}=870 \mathrm{mg} \mathrm{l}^{-1}$

At lower $\mathrm{pH}$, various types of reactions take place as shown below. During these reactions, depending on the solution conditions, some different sites can be formed on the mineral surface.

$$
\begin{aligned}
& =\mathrm{OH}^{-}+\mathrm{H}^{+}=>\mathrm{OH}_{2}^{+} \\
& =\mathrm{PO}_{4}^{3-}=>\mathrm{HPO}_{4}^{-} \\
& =\mathrm{HPO}_{4}^{-}+\mathrm{H}^{+}=>\mathrm{H}_{2} \mathrm{PO}_{4}^{-} \\
& =\mathrm{Ca}^{2+}+\mathrm{OH}^{-}=>\mathrm{CaOH} \\
& =\mathrm{PO}_{4}^{3-}+\mathrm{Ca}^{2+}=>\mathrm{PO}_{4} \mathrm{Ca} \\
& =\mathrm{HPO}_{4}^{-}+\mathrm{Ca}^{2+}=>\mathrm{HPO}_{4} \mathrm{Ca}^{2+}
\end{aligned}
$$

These reactions explain the generation of anionic and cationic charges on the surface. At lower $\mathrm{pH}$ the surface tends toward the positively charged surface sites.

3.10. Adsorption isotherms. The Langmuir and Freundlich equations are commonly used for describing adsorption equilibrium of adsorbate onto the adsorbent. The Langmuir isotherm is applicable to monolayer chemisorptions, while the Freundlich isotherm is used to describe adsorption on surfaces having heterogeneous energy distribution:

The linear equation for Freundlich is given by [20]:

$$
\log q_{e}=\frac{1}{n} \log C_{e}+\log k_{f} \text {, }
$$

where: $\mathrm{K}_{\mathrm{f}}\left(\mathrm{L} \mathrm{mg}^{-1}\right)$ and $1 / \mathrm{n}$ are the Freundlich empirical constants related to the total adsorption capacity of the solid, and the Freundlich exponent, respectively.

And for Langmuir it is given by [21]:

$$
\frac{\mathrm{C}_{\mathrm{e}}}{\mathrm{q}_{\mathrm{e}}}=\frac{1}{\mathrm{k}_{\mathrm{L}} \mathrm{q}_{\max }}+\frac{\mathrm{C}_{\mathrm{e}}}{\mathrm{q}_{\max }},
$$

where: $\mathrm{q}_{\mathrm{e}}\left(\mathrm{mg} \mathrm{g}^{-1}\right)$ is the amount adsorbed on HAp at equilibrium, and $\mathrm{q}_{\max }\left(\mathrm{mg} \mathrm{gm}^{-1}\right)$ is the maximum adsorption monolayer capacity. $\mathrm{k}_{\mathrm{L}}$ is the Langmuir constant related to the affinity between the adsorbate and the adsorbent, and is related to the free energy of adsorption. $\mathrm{C}_{\mathrm{e}}\left(\mathrm{mg} \mathrm{L}^{-1}\right)$ is the concentration of cobalt in liquid phase at equilibrium.

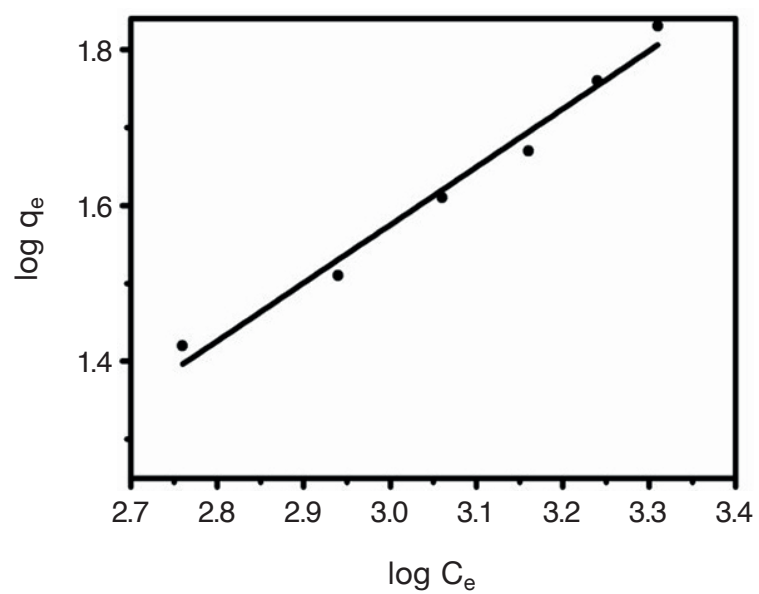

Fig. 11. The Freundlich isotherm plot for cobalt adsorption onto HAp nanopowder

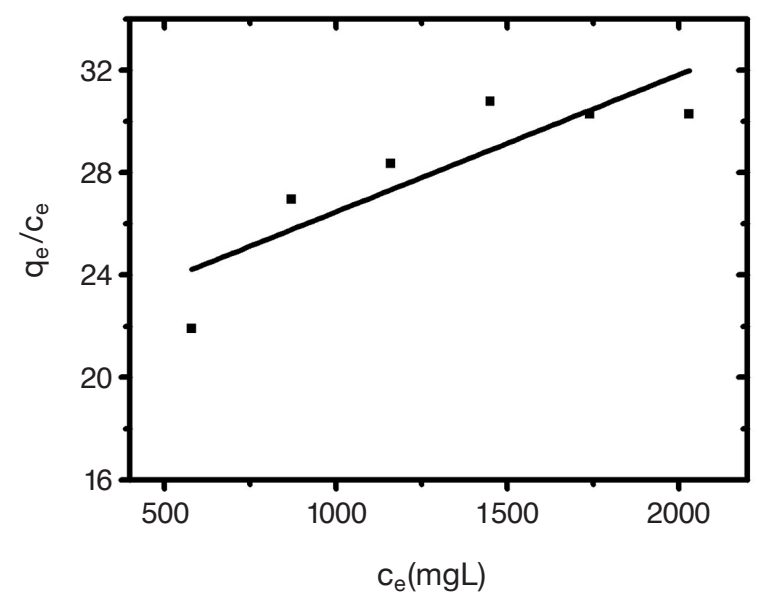

Fig. 12. The Langmuir isotherm plot for cobalt adsorption onto HAp nanopowder

Table 1

Various parameters of Freundlich and Langmuir isotherms

\begin{tabular}{|l|l|l|}
\hline Isotherm & Freundlich & Langmuir \\
\hline & $\mathrm{k}_{\mathrm{f}}=0.3019$ & $\mathrm{q}_{\max }=140$ \\
Parameters & $1 / \mathrm{n}=0.6982$ & $\mathrm{k}_{\mathrm{L}}=0.000366$ \\
& $\mathrm{R}^{2}=0.97$ & $\mathrm{R}^{2}=0.78$ \\
\hline
\end{tabular}


3.11. Kinetic modeling. Knowledge of the kinetic constituents of adsorption is the first step in the investigation of the possibility of using an adsorbent for a particular separation task. In this study, the first-order kinetic model and pseudo-second order kinetic model was used to elucidate the adsorption mechanism. The first-order kinetic model is given as [22]:

$$
\frac{1}{q_{t}}=\frac{k_{1}}{q_{1}} \frac{1}{t}+\frac{1}{q_{1}} \text {, }
$$

where: $\mathrm{q}_{1}$ and $\mathrm{q}_{\mathrm{t}}$ are the amounts of cobalt particles adsorbed on the adsorbent at equilibrium (in $\mathrm{mg} \mathrm{g}^{-1}$ ) and at various time $\mathrm{t}$, respectively, and $\mathrm{k}_{1}$ is the rate constant $\left(\mathrm{min}^{-1}\right)$ of the first-order model for the adsorption process. Values of $\mathrm{k}_{1}$ are calculated from the slope of the plots of $1 / q_{t}$ against $1 / t$.

The pseudo-second-order kinetic model is expressed as [21]:

$$
\frac{\mathrm{t}}{\mathrm{q}_{\mathrm{t}}}=\frac{1}{\mathrm{k}_{2} \mathrm{q}_{2}^{2}}+\frac{\mathrm{t}}{\mathrm{q}_{2}} \text {, }
$$

where: $\mathrm{q}_{2}$ is the maximum adsorption capacity $\left(\mathrm{mg} \mathrm{g}^{-1}\right)$ for the pseudo-second order adsorption, $\mathrm{q}_{\mathrm{t}}$ is the amount of cobalt adsorbed at equilibrium $\left(\mathrm{mg} \mathrm{g}^{-1}\right)$ at time $\mathrm{t}(\mathrm{min})$ and $\mathrm{k}_{2}$ is the rate constant of the pseudo-second order adsorption $\left(\mathrm{g} \mathrm{mg}^{-1} \mathrm{~min}^{-1}\right)$. Values of $\mathrm{k}_{2}$ and $\mathrm{q}_{2}$ are calculated from the plot of $1 / \mathrm{q}_{\mathrm{t}}$ versus $\mathrm{t}$.

Table 2 describes various parameters of the first-order kinetic model and pseudo-second order kinetic model.

Table 2

Parameters of the first- and second-order kinetic models

\begin{tabular}{|l|l|c|}
\hline Kinetic model & First order & Pseudo-second order \\
\hline \multirow{3}{*}{ Parameters } & $\mathrm{k}_{1}=0.2382$ & $\mathrm{k}_{2}=0.02635$ \\
& $\mathrm{q}_{1}=126.744$ & $\mathrm{q}_{2}=127.06$ \\
& $\mathrm{R}^{2}=0.87$ & $\mathrm{R}^{2}=0.99$ \\
\hline
\end{tabular}

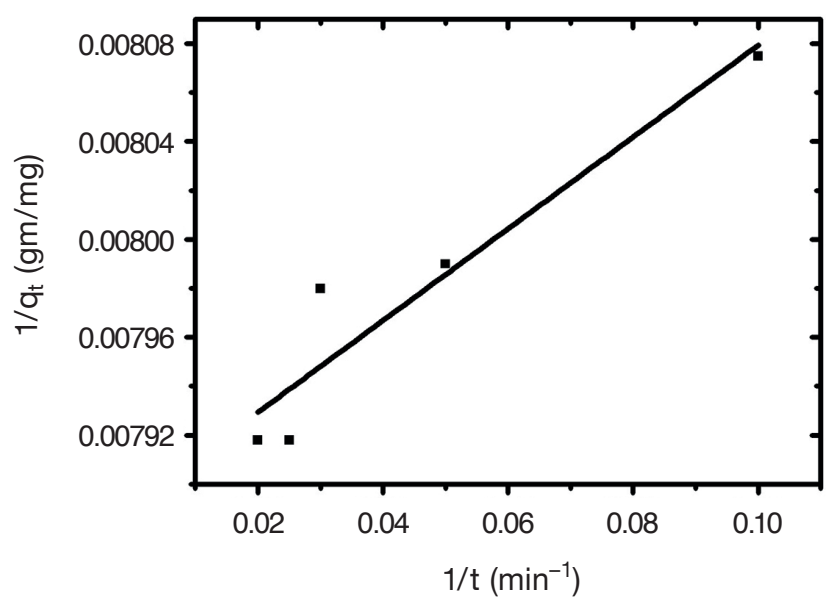

Fig. 13. The first order kinetic model of cobalt adsorption onto HAp at room temperature

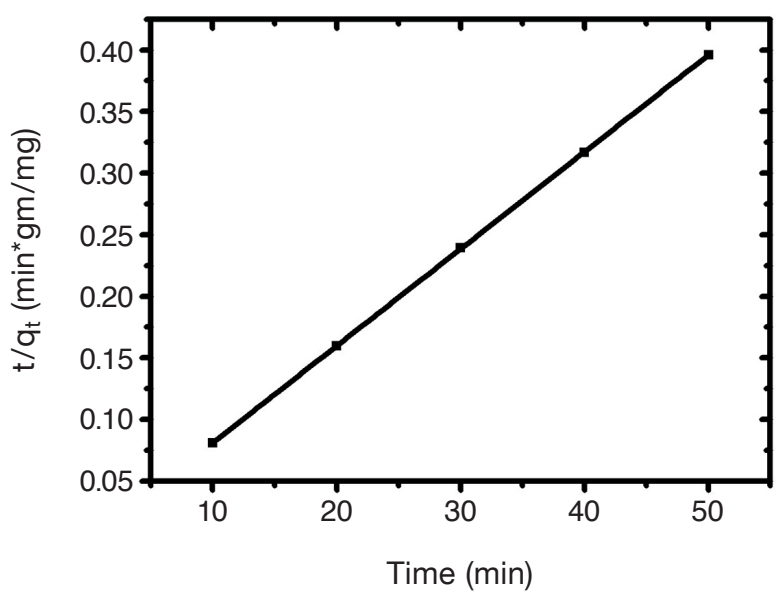

Fig. 14. The second order kinetic model of cobalt adsorption onto HAp at room temperature

The correlation coefficient values $\left(\mathrm{R}^{2}\right)$ range between zero and one. The $\mathrm{R}^{2}$ value nearing to unity shows the best fitted model [22]. Here, the value of $\mathrm{R}^{2}(0.99)$ for the second-order kinetic model is much higher than first-order (0.87) kinetic model, indicating that pseudo second order model is the most suitable for Co adsorption.

\section{Discussion}

HAp $\left(\mathrm{Ca}_{10}\left(\mathrm{PO}_{4}\right)_{6}(\mathrm{OH})_{2}\right)$ contains the $\mathrm{Ca}^{2+},\left(\mathrm{PO}_{4}\right)_{6}$, and $(\mathrm{OH})_{2}$ groups. These groups are ion-exchangeable. The $\mathrm{Ca}^{2+}$ cation is easily ion-exchangeable with various divalent metals. The mechanisms of metal cations retention by HAp include ion exchange, adsorption, dissolution-precipitation, and substitution of $\mathrm{Ca}^{2+}$ ions in mineral structure. Here in our study, $\mathrm{Ca}$ has a cationic radius of $0.99 \AA$ and $\mathrm{Co}$ has a cationic radius $0.745 \AA$. Moreover, both cations have the same oxidation state of 2 . So, it is expected that Co gets ion-exchanged with $\mathrm{Ca}$ easily. The adsorption of ions on HAp could be a combination of two mechanisms. The first one is ion exchange between Co ions contained in the contaminated solution and the $\mathrm{Ca}^{2+}$ cations present in the HAp. This ion exchange process is done through the dissolution of apatite followed by precipitation, according to following equation:

$$
\begin{aligned}
& \mathrm{Ca}_{10}\left(\mathrm{PO}_{4}\right)_{6}(\mathrm{OH})_{2}+\mathrm{x} \mathrm{Co} \rightarrow \\
\rightarrow & \mathrm{Ca}_{10 \mathrm{x}} \mathrm{Co}_{\mathrm{x}}\left(\mathrm{PO}_{4}\right)_{6}(\mathrm{OH})_{2}+\mathrm{x} \mathrm{Ca}^{2+}
\end{aligned}
$$

The second mechanism is that of surface adsorption of Co on HAp. The third mechanism is possibly caused by the formation of complexing of the Co ions with the HAp matrix. This complexing happens due to the dissolution of HAp, followed by precipitation of Cobalt phosphate according to the following two equations:

$$
\begin{aligned}
& \mathrm{Ca}_{10}\left(\mathrm{PO}_{4}\right)_{6}(\mathrm{OH})_{2}+12 \mathrm{H}^{+} \longrightarrow \\
\longrightarrow & 10 \mathrm{Ca}^{2+}+6 \mathrm{H}_{2} \mathrm{PO}^{4-}+2 \mathrm{OH}^{-} \text {(dissolution) }
\end{aligned}
$$




$$
\begin{aligned}
& 10 \mathrm{Co}^{2+}+6 \mathrm{H}_{2} \mathrm{PO}^{4-}+2 \mathrm{OH}^{-} \rightarrow \\
\rightarrow & \mathrm{Co}_{10}\left(\mathrm{PO}_{4}\right)_{6}(\mathrm{OH})_{2}+12 \mathrm{H}^{+} \text {(precipitation) }
\end{aligned}
$$

\section{Conclusion}

In this study, the adsorption potential of HAp nanopowder is investigated for the removal of cobalt from contaminated aqueous solutions. The effect of contact time, initial cobalt concentration, and adsorbent doses on the cobalt adsorption by HAp nanopowder are evaluated. The kinetic equilibrium study of the adsorption of cobalt onto HAp nanopowder is also revealed with variation in cobalt concentration and contact time. The following results are obtained:

The XRD analysis suggests a hexagonal crystal structure of HAp, as all the peaks are well-fitting with the HAp crystal system. TGA/DTA shows that the HAp is thermally stable up to $1000^{\circ} \mathrm{C}$. The functional groups, surface morphology, and elemental analyses of HAp and Co-HAp are visualized by FTIR, AFM, and SEM/EDAX, respectively. Various factors, like the effect of initial concentration, effect of HAp doses, effect of contact time and effect of $\mathrm{pH}$ are studied to check their effect on the adsorption phenomena. Our study shows that adsorption is very fast, as it attains the saturation within 30 minutes. Increasing the initial cobalt concentration and contact time increases the cobalt adsorption capacity. $\mathrm{pH}$ is an influential factor, as the maximum removal occurs at $\mathrm{pH}=6$. The Freundlich isotherm model is best fitted for the adsorption of Co on HAp matrix, indicating multilayer formation. The calculated value for maximum adsorption capacity is $140 \mathrm{mg} \mathrm{gm}^{-1}$. The kinetic data fitting results showed that the adsorption of cobalt on HAp is followed by the pseudo-second order kinetic model as the $\mathrm{R}^{2}$ value is equal to 0.99 .

\section{REFERENCES}

[1] L. Järup, "Hazards of heavy metal contamination", Br. Med. Bull. 68 (1), 167-182 (2003).

[2] S. Martin and W. Griswold, "Human health effects of heavy metals", Environmental Science and Technology briefs for citizens 15, 1-6 (2009).

[3] I. Sargın, M. Kaya, G. Arslan, T. Baran, and T. Ceter, "Preparation and characterisation of biodegradable pollen-chitosan microcapsules and its application in heavy metal removal", Bioresour. Technol. 177, 1-7 (2015).

[4] C. Belviso, F. Cavalcante, S. Di Gennaro, A. Lettino, A. Palma, P. Ragone, and S. Fiore, "Removal of Mn from aqueous solution using fly ash and its hydrothermal synthetic zeolite", J. Environ. Manage. 137, 16-22 (2014).

[5] S. Rengaraj and S.H. Moon, "Kinetics of adsorption of Co (II) removal from water and wastewater by ion exchange resins", Water. Res. 36 (7), 1783-1793 (2002).

[6] D. Baralkiewicz and J. Siepak, "Chromium, nickel and cobalt in environmental samples and existing legal norms", Pol. J. Environ. Stud. 8 (8), 201-208 (1999).
[7] EPA United States Environmental Protection Agency, www.epa. gov/airtoics/hlthef/cobalt.html, (2015).

[8] H.S. Lim, W. Lim, J.Y. Hu, A. Ziegler, and S.L. Ong, "Comparison of filter media materials for heavy metal removal from urban stormwater runoff using biofiltration systems", J. Environ. Manage. 147, 24-33 (2015).

[9] S. Zhang, M.H. Peh, Z. Thong, and T.S. Chung, "Thin film interfacial cross-linking approach to fabricate a chitosan rejecting layer over poly (ether sulfone) support for heavy metal removal", Ind. Eng. Chem. Res. 54 (1), 472-479 (2014).

[10] R. Sitko, P. Janik, B. Zawisza, E. Talik, E. Margui, and I. Queralt, "Green approach for ultratrace determination of divalent metal ions and arsenic species using total-reflection X-ray fluorescence spectrometry and mercapto-modified graphene oxide nanosheets as a novel adsorbent", Anal. Chem. 87 (6), 3535-3542 (2015)

[11] X. Chen, J.V. Wright, J.L. Conca, and L.M. Peurrung, "Evaluation of heavy metal remediation using mineral apatite", Water, Air, Soil, Poll. 98, 57-78 (1997).

[12] R.U. Mene, M.P. Mahabole, K.C. Mohite, and R.S. Khairnar, "Improved gas sensing and dielectric properties of Fe doped hydroxyapatite thick films: Effect of molar concentrations", Mater. Res. Bull. 50, 227-234 (2014).

[13] M.P. Mahabole, R.U. Mene, and R.S. Khairnar, "Gas sensing and dielectric studies on cobalt doped hydroxyapatite thick films", Adv. Mat. Letter. 4 (1), 46-52 (2013).

[14] M.P. Mahabole, R.C. Aiyer, C.V. Ramakrishna, B. Sreedhar, and R.S. Khairnar, "Synthesis, characterization and gas sensing property of hydroxyapatite ceramic", Bull. Mater. Sci. 28 (6), 535-545 (2005).

[15] M.P. Ferraz, F.J. Monteiro, and C.M. Manuel, "hydroxyapatite nanoparticles: a review of preparation methodologies", J. Appl. Biomater. Biomech. 2 (2), 74-80 (2004).

[16] H. Soni, and P. Padmaja, "Palm shell based activated carbon for removal of bisphenol A: an equilibrium, kinetic and thermodynamic study", J. Porous. Mater. 21 (3), 275-284 (2014).

[17] A. Mathew, S. Parambadath, S.Y. Kim, S.S. Park, and C.S. Ha, "Adsorption of $\mathrm{Cr}$ (III) ions using 2-(ureylenemethyl) pyridine functionalized MCM-41", J. Porous. Mater. 22 (3), 831-842 (2015).

[18] H. Morgan, R.M. Wilson, J.C. Elliott, S.E.P. Dowker, and P. Anderson, "Preparation and characterisation of monoclinic hydroxyapatite and its precipitated carbonate apatite intermediate", Biomaterials 21 (6), 617-627 (2000).

[19] J. Barralet, J.C. Knowles, S.Best, and W. Bonfield, "Thermal decomposition of synthesised carbonate hydroxyapatite", J. Mater. Sci. - Mater. Med. 13 (6), 529-533 (2002).

[20] M. Yusuf, L. Chuah, M.A. Khan, and T.S. Choong, "Adsorption of nickel on electric arc furnace slag: batch and column studies", Separ. Sci. Techno. 49 (3), 388-397 (2014).

[21] C.P.Shah, K. Singh,C. Dusane, S. Mishra, G.G. Pandit, M. Kumar, and P.N. Bajaj, "Study of extraction of Co (II) ions using the synthesized polyacrylonitrile-manganese dioxide composite beads", Separ. Sci. Technol. 47 (8), 1177-1184, (2012).

[22] K. Lin, J. Pan, Y. Chen, R. Cheng, and X. Xu, "Study the adsorption of phenol from aqueous solution on hydroxyapatite nanopowders", J. Hazard. Mater. 161 (1), 231-240 (2009). 